\title{
Potentially of Soybean as Bio-Catalyst in Calcite Precipitation Methods for Improving the Strength of Sandy Soil
}

\author{
Luthfi Lofianda $^{1}$, Heriansyah Putra ${ }^{1, *}$, Erizal $^{1}$, Sutoyo $^{1}$, Hideaki Yasuhara ${ }^{2}$ \\ ${ }^{1}$ Department of Civil and Environmental Engineering, IPB University, Bogor, Indonesia \\ ${ }^{2}$ Department of Civil and Environmental Engineering, Ehime University, Matsuyama, Japan
}

Received July 25, 2021; Revised October 20, 2021; Accepted November 11, 2021

\section{Cite This Paper in the following Citation Styles}

(a): [1] Luthfi Lofianda, Heriansyah Putra, Erizal, Sutoyo, Hideaki Yasuhara , "Potentially of Soybean as Bio-Catalyst in Calcite Precipitation Methods for Improving the Strength of Sandy Soil," Civil Engineering and Architecture, Vol. 9, No. 7, pp. 2317 - 2325, 2021. DOI: 10.13189/cea.2021.090719.

(b): Luthfi Lofianda, Heriansyah Putra, Erizal, Sutoyo, Hideaki Yasuhara (2021). Potentially of Soybean as Bio-Catalyst in Calcite Precipitation Methods for Improving the Strength of Sandy Soil. Civil Engineering and Architecture, 9(7), 2317 - 2325. DOI: 10.13189/cea.2021.090719.

Copyright $\bigcirc 2021$ by authors, all rights reserved. Authors agree that this article remains permanently open access under the terms of the Creative Commons Attribution License 4.0 International License

\begin{abstract}
The biocementation-based soil improvement technique that has been recently developed is enzyme-induced calcite precipitation (EICP). Previous studies on the EICP technique used pure commercial urease enzyme as a reaction catalyst to precipitate calcite from urea and calcium chloride. However, pure commercial urease enzyme is inefficient for application on a large scale due to its high price. Therefore, studies reported that soybean is a potential alternative for pure commercial urease enzymes. This study evaluates the strength of sandy soil by treatment using EICP grouting solution with soybean extracts as the bio-catalyst. The extracts used in this study were obtained by filtration and centrifugation treatment. Based on the calcite mass quantification and precipitation ratio, $20 \mathrm{~g} / \mathrm{L}$ soybean extract concentration in both treatments is used for treating the solution. Then, the unconfined compressive strength (UCS) tests were conducted to evaluate the increase of the strength of sandy soil. The maximum UCS value was obtained at the 28 days of curing time in both treatments. The centrifugation treatment has a higher UCS value with $65.6 \mathrm{kPa}$ than the filtration treatment with $53.6 \mathrm{kPa}$. Thus, this study elucidated that soybean extract has a great potential to be a bio-catalyst in the calcite precipitation method.
\end{abstract}

Keywords Calcite Precipitation, Soybean Powder,
Sandy Soil, UCS, Filtration, Centrifugation

\section{Introduction}

Soil improvement techniques based on calcium carbonate $\left(\mathrm{CaCO}_{3}\right)$ or calcite precipitation are composed of microbial-based and enzyme-based techniques. Both methods utilize the urease enzyme to precipitate the calcite from urea and calcium chloride. The bacteria-based technique used the ureocatalytic microbes, i.e., Sporosarcina pasteurii, to produce the urease enzyme [1], [2]. This technique could increase soil stiffness and reduce soil permeability. However, the evolutions in mechanical and physical properties of treated soil induced by microbial activity are hard to predict; thus, the mortality rate of the applied microbes population is difficult to control [3]. According to Putra et al. [4], this technique requires a complex microbial treatment procedure and the growth medium potentially leads to failure in its implementation. Therefore, other methods are needed to produce calcite without microbial culture. Enzyme-induced calcite precipitation (EICP) can form calcite crystals using pure urease enzyme without any need for microbes. The EICP technique could increase soil strength equivalent to a microbial-based method 
without using microbes due to its complex treatment [5]. Through this technique, the grouting solution consists of urea $\left(\mathrm{CO}\left(\mathrm{NH}_{2}\right)_{2}\right)$, calcium chloride $\left(\mathrm{CaCl}_{2}\right)$, and a catalyst agent in the form of the urease enzyme is injected into the soil.

Putra et al. [6] stated that this technique requires many injections to increase a large amount of soil. Soil with 1 $\mathrm{m}^{3}$ volume requires $60 \mathrm{~kg}$ precipitated material to maintain the soil strength in the range of $300 \mathrm{kPa}$ [7]. The price of pure commercial urease enzyme is high and ineffective if used on a large scale, so it requires pure commercial urease enzyme substitute without reducing the effectiveness of the EICP technique in soil improvement [8]. Various previous studies proved that soybean could be used as a potential alternative source of urease enzyme. The study conducted by Pratama et al. [9] proved that soybean extract has urease specific activity up to $74.2 \mathrm{U} / \mathrm{g}$, which is 675.5-827.9 $\mathrm{U} / \mathrm{g}$ in pure commercial urease enzyme or about $10 \%$ of the pure urease enzyme yield. Meisnnehr et al. [10] evaluated the addition of $60 \mathrm{~g} / \mathrm{L}$ soybean extract in a grouting solution that used pure urease enzyme and achieved the shear strength value of $180 \mathrm{kPa}$ for sandy soil.

The utilization of soybean extract in grouting solution could be treated by filtration (sieve) or centrifugation treatment. Pratama et al. [9], Baiq et al. [11], Lee and Kim [12] evaluated the centrifugation treatment using 20 minutes of centrifugation to obtain the supernatant soybean extract and separated it with undissolved soybean. Utilization of soybean extract obtained from centrifugation treatment could increase the shear strength of sandy soil up to $600 \mathrm{kPa}$ [9], [12]. This treatment could also produce a calcite precipitation mass ratio of up to $63 \%$ of the precipitation mass-produced using pure urease enzyme [11]. Centrifugation treatment with a short time will increase the rate of hydrolysis reaction by the enzyme, but it takes a long time to obtain the supernatant if used in large quantities [13]. Therefore, the filtration treatment is proposed to produce the soybean extract that does not take long. So far, filtration treatment for the mixture of soybean powder and water has never been conducted. However, Cuccurullo et al. [8] used soybean extract in soybean juice from soybean powder and water mixture without any filtration.

This study compares the filtration and centrifugation treatment to obtain the soybean extract. Filtration treatment is easier and faster to conduct because it does not require a long time. However, filtration treatment will produce undissolved soybean that passes through the sieve depending on the sieve diameter. The utilization of soybean extract from both treatments is evaluated based on the increase in shear strength parameter through the UCS test. Sandy soil shear strength parameter could be improved in line with the decrease of soil permeability and compressibility through this technique. Yasuhara et al. [3] and Putra et al. [4] evaluated the increase in sandy soil shear strength by 0.4-1.6 MPa through the calcite precipitation technique. Therefore, it is necessary to assess the utilization of soybean extract obtained from filtration and centrifugation treatment as a substitute for urease enzyme to improve the shear strength parameter of sandy soil.

\section{Materials and Methods}

\subsection{Materials}

The primary materials such as urea $\left(\mathrm{CO}\left(\mathrm{NH}_{2}\right)_{2}\right)$, calcium chloride dihydrate $\left(\mathrm{CaCl}_{2} \cdot 2 \mathrm{H}_{2} \mathrm{O}\right)$, and hydrochloric acid $(\mathrm{HCl})$ were obtained from EMSURE ${ }^{\circledR}$ ACS, Reag. Ph. Eur. The soybean powder (Gasol Soybean Flour 200 g) was obtained from PT. Gasol Organik, South Jakarta, Indonesia. The sandy soil used as samples was graduated sand SO-404, classified as poorly graded sand (SP). Graduated sand SO-404 has $\mathrm{e}_{\max }, \mathrm{e}_{\min }$, coefficient of uniformity (Cu), and specific gravity (Gs) of 0.802, 0.543, 2.26, and 2.61. The grain size distribution curve of graduated sand SO-404 is shown in Fig. 1.

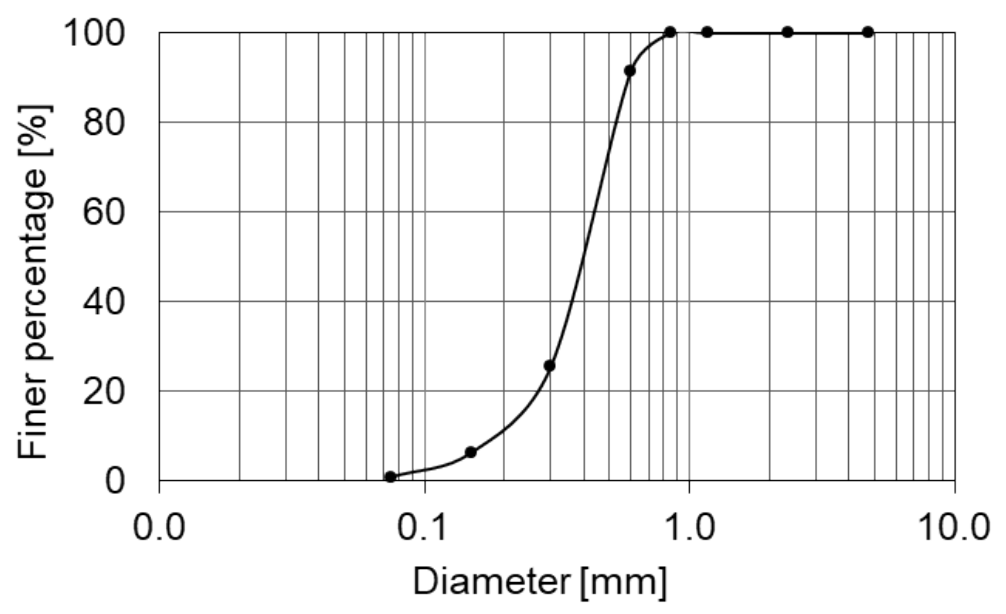

Figure 1. Grain size distribution curve of graduated sand SO-404 


\subsection{Precipitation Test}

Table 1. Experimental condition of the precipitation test

\begin{tabular}{cccc}
\hline Case & \multicolumn{3}{c}{ Concentration } \\
\cline { 2 - 4 } & $\begin{array}{c}\mathbf{C O}\left(\mathbf{N H}_{2}\right)_{2} \\
(\mathbf{m o l} / \mathbf{L})\end{array}$ & $\begin{array}{c}\mathbf{C a C l}_{\mathbf{2}} \mathbf{2} \mathbf{H}_{\mathbf{2}} \mathbf{O} \\
(\mathbf{m o l} / \mathbf{L})\end{array}$ & $\begin{array}{c}\text { Soybean } \\
\mathbf{( g / L )}\end{array}$ \\
\hline F1 & 1.0 & 1.0 & 10.0 \\
F2 & 1.0 & 1.0 & 20.0 \\
F3 & 1.0 & 1.0 & 30.0 \\
F4 & 1.0 & 1.0 & 40.0 \\
F5 & 1.0 & 1.0 & 50.0 \\
\hline C1 & 1.0 & 1.0 & 10.0 \\
C2 & 1.0 & 1.0 & 20.0 \\
C3 & 1.0 & 1.0 & 30.0 \\
C4 & 1.0 & 1.0 & 40.0 \\
C5 & 1.0 & 1.0 & 50.0 \\
\hline
\end{tabular}

The grouting solution preparation was adopted from that procedure proposed by Putra et al. [14]. A precipitation test was conducted to evaluate the precipitation mass-produced in the grouting solution after curing time. First, each reagent and catalyst (soybean powder) was mixed with distilled water using a magnetic stirrer for 5 minutes. Then, the mixture of soybean powder and distilled water was prepared using filtration and centrifugation treatment methods. In the filtration process, the soybean solution directly pours to a sieve number 200 $(0.075 \mathrm{~mm})$, and the passed materials were used as the catalyst solution. In the centrifugation treatment, the soybean solutions are centrifuged using an LC-04R with a rate of $3000 \mathrm{rpm}$ for 20 minutes. Thus, the supernatant solution was collected as the catalyst solution-each catalyst solution mixed with the reagent to make a $30 \mathrm{~mL}$ grouting solution in a tube. Finally, the samples were incubated for seven days of curing time. The experimental condition of the precipitation test is shown in Table 1 . Cases of $\mathrm{F}$ and $\mathrm{C}$ refer to the filtration and centrifugation treatment, respectively.

\subsection{Calcite and Undissolved Soybean Mass Quantification}

Calcite mass and undissolved soybean were evaluated to determine the actual calcite mass composition and precipitation tubes. This test assessed the calcite mass precipitated in every concentration of soybean extract and reagents from both treatments. After the precipitation test, tubes are dried using the oven, hydrochloric acid diluted to $10 \%$ is poured into tubes. Hydrochloric acid will dissolve calcite in a tube and leave the undissolved soybean mass. Therefore, the mass difference between actual precipitation mass and undissolved soybean mass is the actual calcite precipitated in a tube.

\subsection{Unconfined Compressive Strength (UCS) Test}

The optimum concentration of soybean, indicated by the precipitated mass, was selected for application in the soil. The soil samples were prepared in cylinder molds with 5 $\mathrm{cm}$ diameter and $10 \mathrm{~cm}$ height with a relative density (Dr) of $50 \%$. The treatment process was conducted by pouring one pore volume (PV) of the solution from the top of the sample. Thus, the treated soil samples were kept for various curing times of 7,14 , and 28 days. UCS test was conducted to evaluate the effect of EICP solution on the shear strength parameter of sandy soil. After curing time, the samples were removed from cylinder molds. Thus, the surface of samples should be flattened before the UCS test is conducted.

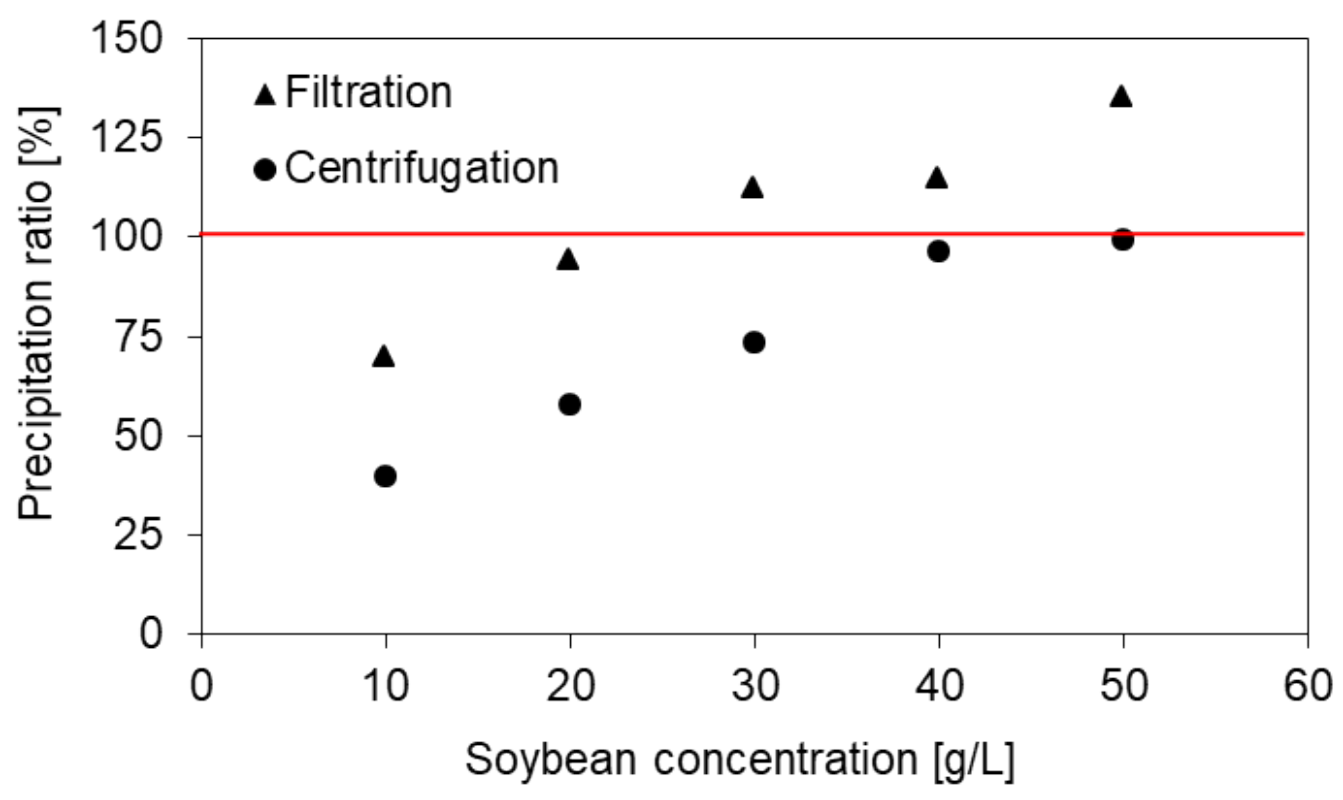

Figure 2. Precipitation ratio of every soybean extract concentrations on both treatments 


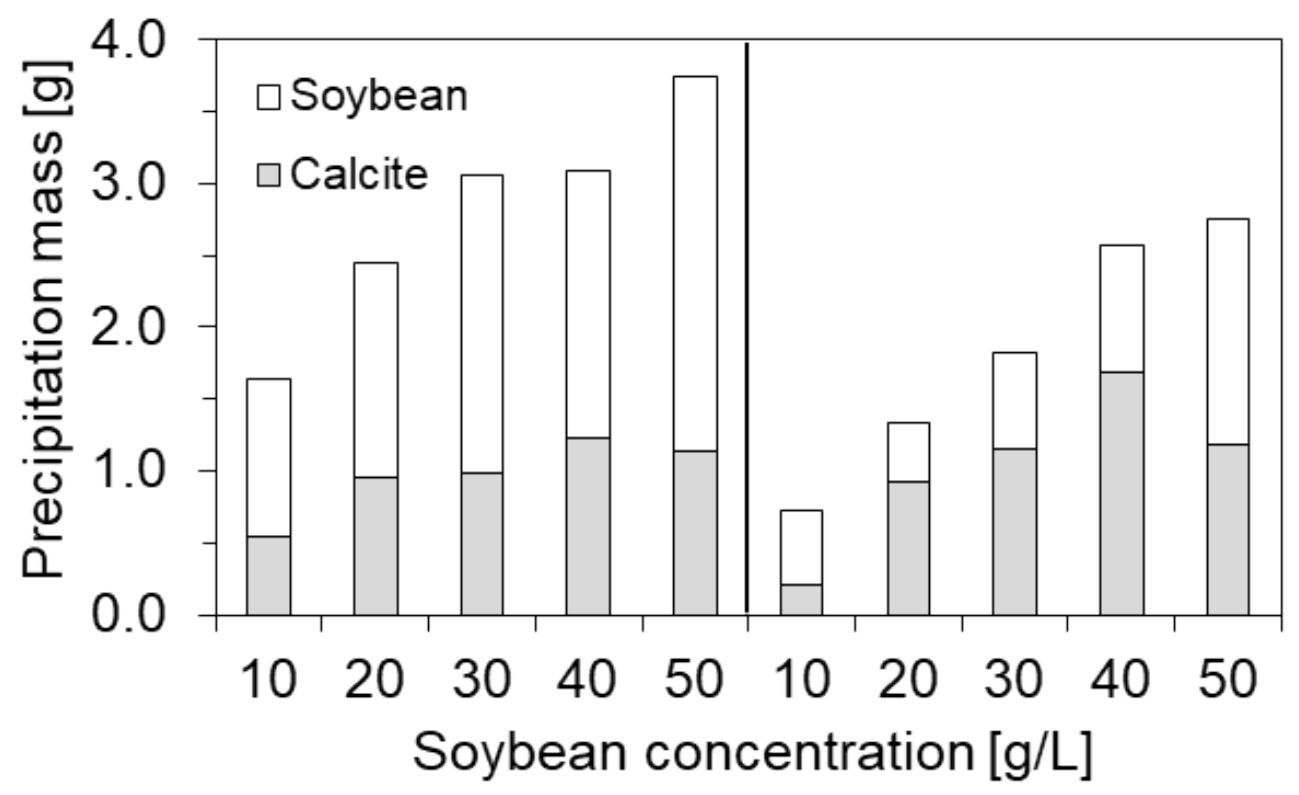

Figure 3. Composition of calcite and undissolved soybean mass

\section{Result and Discussion}

\subsection{Precipitation Test Evaluation}

The optimum soybean concentration used in sandy soils was evaluated based on the results of precipitation tests. Precipitation tests were conducted on both types of soybean extract treatment, based on Table 1 . The mass ratio of precipitation was calculated using the ratio between the actual mass of precipitation formed at each concentration with the mass of calcite theoretically formed through the hydrolysis reaction (3g). The precipitation ratio of every soybean extract concentration on both treatments can be seen in Fig. 2.

The result of precipitation ratio with filtration treatment is relatively higher than centrifugation treatment. Precipitation ratios with filtration treatment at concentrations of $30-50 \mathrm{~g} / \mathrm{L}$ are exceeded $100 \%$. These indicate that the actual precipitation mass formed after the precipitation test is higher than theoretically-formed calcite mass. The highest precipitation ratio occurred at a soybean concentration of $50 \mathrm{~g} / \mathrm{L}$, which was $135.6 \%$ on filtration treatment and $99.4 \%$ on centrifugation treatment. The precipitation test evaluated by Lee and Kim [12] showed that using 40-50 g/L soybean extract with centrifugation treatment in $1 \mathrm{~mol} / \mathrm{L}$ reagent had a precipitation ratio of more than $80-90 \%$. Baiq et al. [11] also evaluated the precipitation ratio using $15 \mathrm{~g} / \mathrm{L}$ soybean extract with a precipitation ratio of $55 \%$ with centrifugation treatment. The $15 \mathrm{~g} / \mathrm{L}$ concentration was not used in this evaluation. However, the resulting trend showed that the precipitation ratio of that concentration was around $50 \%$ which corresponded to the result evaluated by Baiq et al. [11]. Fig. 2 shows that the soybean of $40-50 \mathrm{~g} / \mathrm{L}$ in the filtration method results in the precipitation ratio at $40-50 \mathrm{~g} / \mathrm{L}$ soybean extract concentration in the filtration treatment is more than $90 \%$. Overall, the higher soybean concentration from both treatments that were added into reagents also shows the higher precipitation ratio. This increase indicates that the higher the concentration of soybean used, the faster urea hydrolysis will be, resulting in more calcite mass precipitated [12].

\subsection{Calcite and Undissolved Soybean Mass Quantification}

The precipitation ratio analysis shows that some concentrations have a precipitation ratio of more than $100 \%$ and indicate that the amount of actual precipitation mass exceeds the theoretical mass. In general, the actual yield of precipitation mass is always less than the theoretical yield. It may be because the reagent that has functioned as a limiter is not fully decomposed because the reaction has been completed before all reagents are fully decomposed [15]. Putra et al. [5] suspected that precipitation ratio excess of $100 \%$ indicates that there are still substances other than calcite in grouting solution. The remaining mass in the tube other than calcite is undissolved soybean mass. Undissolved residue can reduce the permeability of treated sand but can not increase soil shear strength [16]. It happens because only calcite minerals can bind the soil grains. Therefore, it is necessary to measure calcite and undissolved soybean mass after the precipitation test is conducted. Cuccurullo et al. [8] stated that utilization of soybean powder in EICP solution would leave the undissolved soybean paste. This paste has a high consistency but does not contain calcite. The filtration treatment on soybean extract resulted in soybean powder grains being insoluble in water but passed the sieve. It 
occurs because the soybean grains size was smaller than the diameter of the sieve $(0.075 \mathrm{~mm})$. The composition of calcite and undissolved soybean mass is shown in Fig. 3.

According to the calcite and undissolved soybean mass composition, the maximum calcite mass is formed at 20 $\mathrm{g} / \mathrm{L}$ soybean concentration in the filtration treatment and $40 \mathrm{~g} / \mathrm{L}$ in centrifugation treatment. Putra et al. [5] stated that the higher catalyst concentration in the EICP solution caused the higher mass of insoluble catalyst in the filtration process with filter paper. As a result, the formation of precipitation material becomes less effective because undissolved material can affect the calcite formation reaction in EICP solution. Fig. 3 shows that the mass of undissolved soybean left exceeds the mass of added soybean. This result could happen due to the production of soybean solution being made in large quantities for one concentration. XRD test can be conducted for a more detailed analysis of calcite and undissolved soybean [7]. Overall, precipitated calcite in centrifugation treatment is higher than filtration treatment.

Based on the actual calcite mass, it is known that soybean extract obtained by centrifugation treatment is better than filtration treatment due to the higher amount of precipitated calcite. Centrifugation treatment of soybean powder caused the plant cell wall to be destroyed in the process and caused the plasma membrane and nutrients inside the soybean to get out of the cells. Nutrients contain various kinds of proteins, fats, and sugars, including enzymes [17]. Therefore, the urease enzyme contained in soybean plant cells can be optimally extracted through centrifugation treatment. The centrifugation process of soybean produces nutrient-rich supernatant and fiber-rich undissolved soybean or pellets [18]. The nutrients, including the urease enzyme contained in the supernatant, were higher than the filtered soybean solution. Optimum enzyme extraction will result in higher precipitation mass due to increased reaction rate and urease enzyme activity [19]. In addition, the supernatant produced by the centrifugation process can increase the rate of hydrolysis reaction [13]. Cuccurullo et al. [8] proved that at a one $\mathrm{mol} / \mathrm{L}$ reagents concentration, soybean extract in the form of supernatant had higher urease enzyme activity than soybean extract obtained from soybean powder solution. Based on these statements, the soybean extract obtained by centrifugation treatment is better than filtration treatment.

The increase in soybean extract concentration for treatments resulted in a rise in the undissolved soybean. The undissolved soybean mass left in the filtration treatment is higher than in the centrifugation treatment. More than $65 \%$ of the soybean meal (soybean powder) mass has a grain size diameter of more than $841 \mu \mathrm{m}$ [20], so the large amount of undissolved soybean mass that is detained in the sieve was in the grain size diameter range of $841 \mu \mathrm{m}$ to $75000 \mu \mathrm{m}(0.075 \mathrm{~mm})$ as the sieve diameter size. The precipitated mass in the form of undissolved soybean is no longer in granular form because the supernatant contains only nutrients found in soybean plant cells [18] and passed the filter paper with a diameter of 20-25 $\mu \mathrm{m}$. Therefore, the undissolved soybean mass in centrifugation treatment that could affect the reaction is lower than in the filtration treatment.

The $20 \mathrm{~g} / \mathrm{L}$ soybean concentration is selected for grouting solution on sandy soil samples due to the optimum calcite mass in the filtration treatment compared to other soybean concentrations. Pratama et al. [9] evaluated that $20 \mathrm{~g} / \mathrm{L}$ soybean extract concentration from centrifugation treatment has optimum urease enzyme activity. Putra et al. [5], [4], and [14] used two g/L of pure commercial urease enzyme was used in various studies. According to Pratama et al. [9], the pure commercial urease enzyme of $2 \mathrm{~g} / \mathrm{L}$ results in a similar urease enzyme activity to $20 \mathrm{~g} / \mathrm{L}$ of soybean. Therefore, the soybean extract concentration of $20 \mathrm{~g} / \mathrm{L}$ is used for grouting solution to sandy soil samples.

\subsection{UCS Test}

The UCS test evaluated the shear strength parameter of sandy soil. The tests were conducted to obtain the cohesion of sandy soil after being treated by EICP solution. The samples were tested after 7,14 , and 28 days of curing time. The result of the UCS values of treated sand in varying curing times is shown in Fig. 4.

There was an increase in the value of UCS along with the addition of curing time after injection. The UCS values of samples at seven days with filtration and centrifugation treatment were 27.4 and $44.7 \mathrm{kPa}$, respectively. Subsequently, UCS values increased to maximum values at 28 days with filtration and centrifugation treatment were $53.6 \mathrm{kPa}$ and $65.6 \mathrm{kPa}$. The increase of the UCS value rate that occurred in the filtration treatment was higher than in centrifugation treatment. The rise in UCS value for centrifugation treatment reaches the maximum point faster than filtration treatment. It occurs because the increase in urease enzyme concentration is proportional to the rise in the initial reaction rate and product concentration (calcite) [21]. Therefore, soybean extract with centrifugation treatment was considered a more optimum urease enzyme than filtration treatment. The increase of the initial reaction rate causes the time to achieve maximum calcite precipitation to be shorter. 


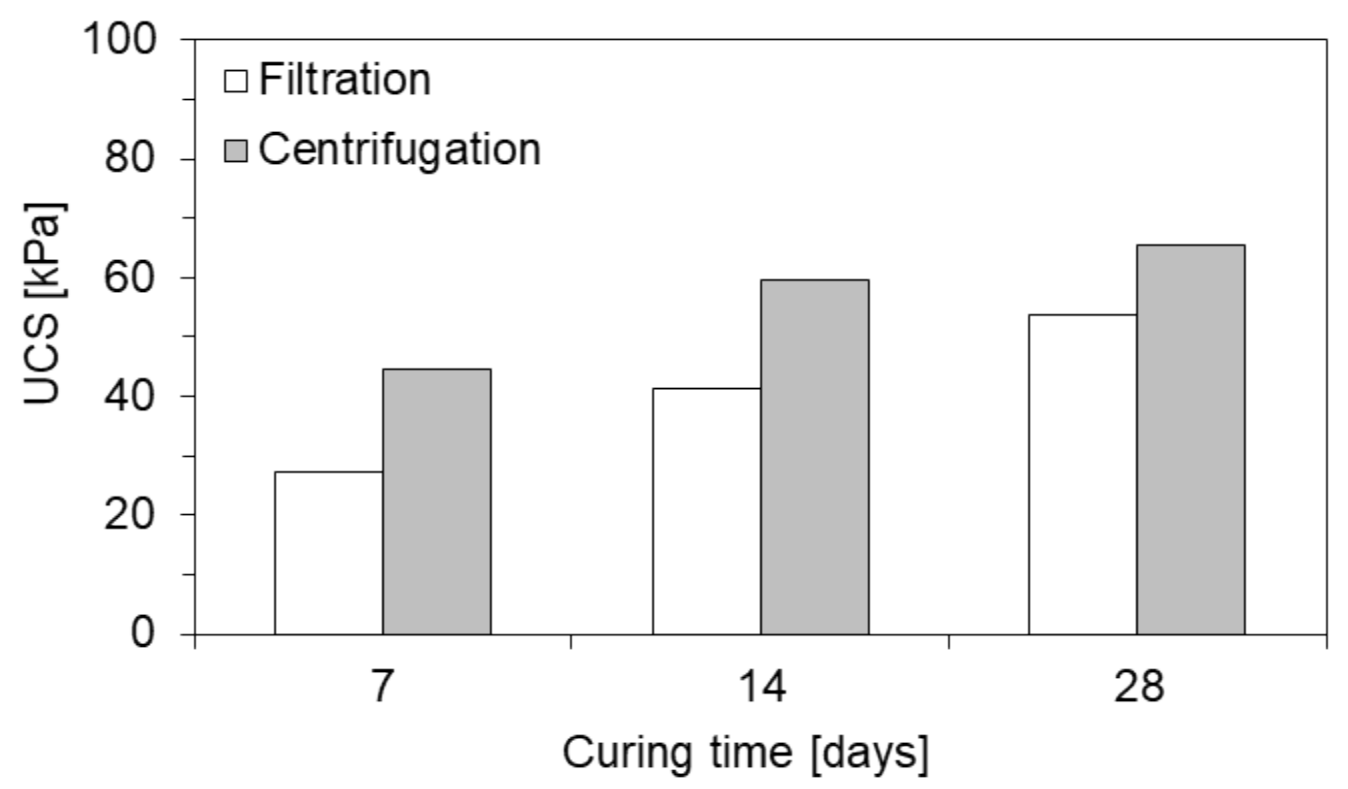

Figure 4. UCS values of treated sand for varying curing time

Lee and Kim [12] evaluated that treated sand had optimum UCS values at 14 days of curing time. This result shows that the optimum UCS values were achieved at 28 days of curing time. However, the UCS values of this result are still relatively lower than Pratama et al. [9], which reached $64.7 \mathrm{kPa}$ at seven days of curing time with centrifugation treatment. Baiq et al. [22] evaluated an increase in UCS values of $100 \mathrm{kPa}$ in 3 days of curing time to $190 \mathrm{kPa}$ in 7 days of curing time or about $90 \%$. Rohy et al. [23] also evaluated that 3 to 7 days of curing time can increase UCS value up to $600 \%$ from $500 \mathrm{kPa}$ to $3 \mathrm{MPa}$. The effect of curing time on the increase in UCS value can be caused due to the rise in the rate of calcite production and the increase of curing time. Based on the calcite precipitation reaction in the EICP technique, urease will continue to be used as a catalyst for the calcite precipitation reaction until the reagents are completely decomposed [24]. Therefore, the increase in curing time affects the growth of treated sand UCS value. The treated sand samples after curing time are shown in Fig. 5. The main difference of the treated samples from both treatments is that the calcite distribution from centrifugation treatment was more uniformly distributed than filtration treatment. Fig. 5 shows that the bottom part of the sample with filtration treatment was segregated compared to the top position. It occurs because the samples in the filtration treatment have a 1-2 mm thick white sediment layer as the accumulation of precipitation material that is retained in the surface. This layer can affect the distribution of calcite throughout the sample as it is retained on the top part of the sample. Samples with centrifugation treatment had no white sediment layer on the surface because no undissolved soybean settled on the supernatant and reagents solution. This results in the solution can reach the pore space of the treated sand optimally. The uniformity effect is related to the injection method, which used direct pouring on the top of the sample. Chen et al. [25] stated that injection of EICP solution by direct pouring is more easily stable. However, the distribution of calcite deposits is not uniform, and the mass of precipitated calcite outside the injection point is lower than in the injection point. It made the bottom part of treated sands segregated and weaker than the injection point of the top part. The uniformity of calcite distribution on treated sand is an essential aspect of the EICP technique. Optimum contact between soil grains is required to obtain high shear strength and stiffness. The uniform calcite distribution shows that the calcite sheath and joints have an equal distribution in each grain [26]. Hence, SEM analysis is required to determine the actual calcite precipitation distribution at the soil grain level. In addition, it is necessary to analyze the calcite distribution in every segment to determine the uniformity effect on every part. Putra et al. [4] and Neupane et al. [27] evaluated the calcite distribution in a $1 \mathrm{~m}$ sand column and showed that the highest calcite distribution occurred near the inlet. The soil grain size also affects the distribution of the sample. The interparticle interaction force (adhesion) increases along with the bigger size of the particle [28]. Therefore, adhesion between soil and calcite particles will decrease along with the smaller size of soil grains. 

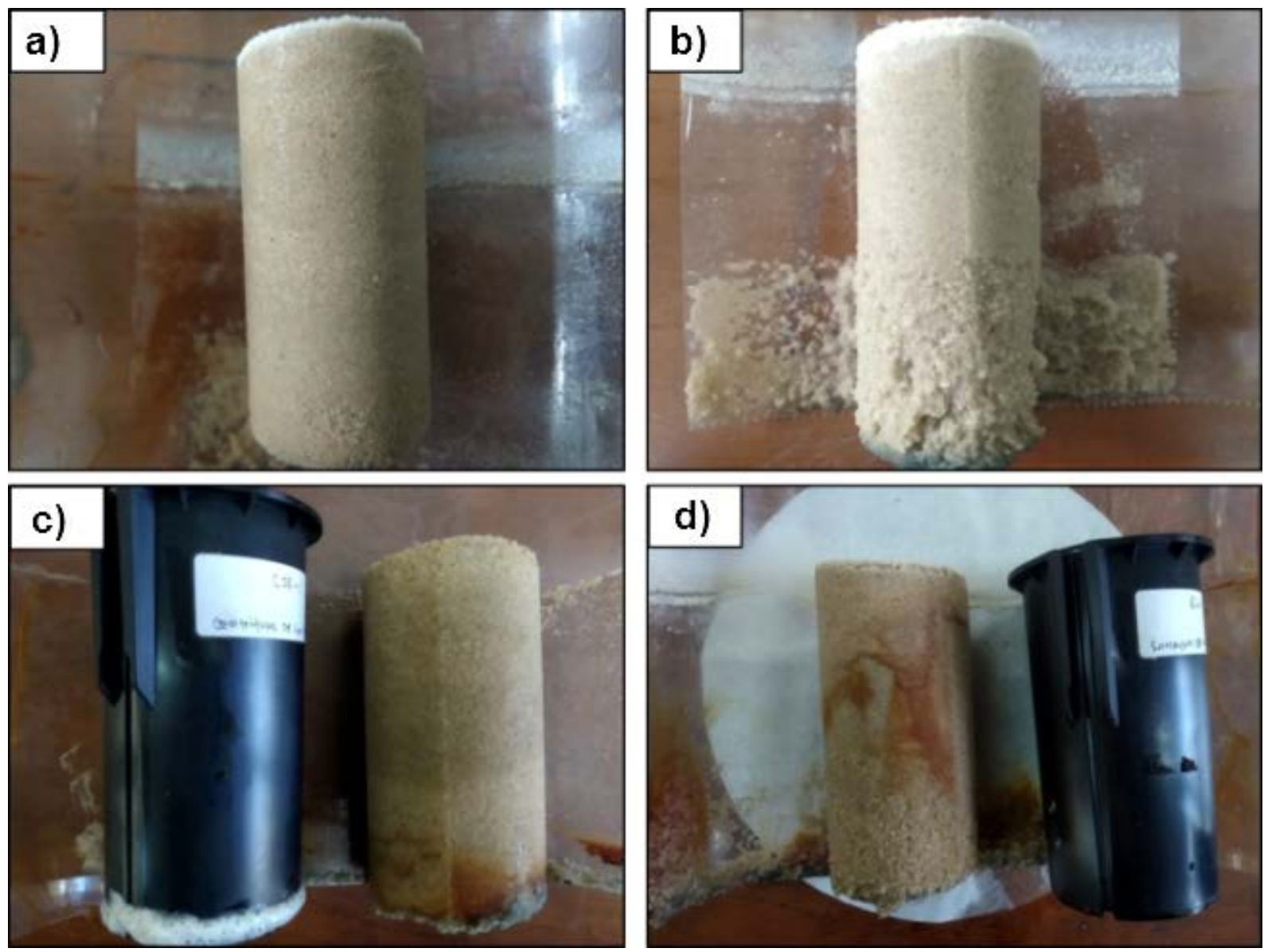

Figure 5. Treated sand samples of curing time (a) centrifugation treatment at 28 days (b) filtration treatment at seven days (c) centrifugation treatment at 28 days (d) centrifugation treatment at 28 days

Calcite distribution also affects the failure mechanisms during the UCS test. The failures happened when the calcite-calcite and calcite-soil bonds in treated samples were broken after the applied loading [26]. Through the UCS test, the groove pattern formed the ring layer from the bottom to the top of the sample. The result showed that the failure pattern is perpendicular to the direction of the groove pattern with an inclination angle up to 90o, which is categorized as tensile splitting or axial failure [29]. The crack begins in the weakest part of the sample and continues until failure occurs throughout the sample. The failure mechanism of treated sands is shown in Fig. 6.

The tensile splitting has occurred in all the samples after the UCS test. Almajed et al. [30] also evaluated this failure model in treated sand using milk powder as a urease substitute on EICP solution. Almajed et al. [30] predicted that using organic material as the urease substitute would cause a low precipitation rate than pure commercial urease. The precipitated calcite has a bigger size, reducing pore spaces accessibility by EICP solution and concentrating as the grain surface sheath. When the applied load reaches the maximum point, failure will occur because the calcite bond fails to bind the grain particles, and hence, the sample will fail with the tensile splitting mechanism.

\section{Conclusion}

The applicability of soybean powder as a bio-catalyst in the calcite precipitation method has been evaluated. The mass of precipitation increased with the addition of the concentration of soybean extract on both filtration and centrifugation treatments, with the optimum concentration of $20 \mathrm{~g} / \mathrm{L}$. The results of the UCS test on treated sand with filtration and centrifugation treatment at 7, 14, and 28 days of curing time showed an increase in the strength of the soil. The maximum UCS was formed at 28 days with filtration treatment of $53.6 \mathrm{kPa}$ and centrifugation of 65.6 $\mathrm{kPa}$. The UCS test result also shows that the failure mechanism tensile split has occurred in the treated samples. Based on the value of precipitation ratio and the value of UCS, the best method to obtain soybean extract for EICP solution is by using centrifugation treatment. Through the centrifugation process, nutrients, including enzymes contained in soybean plant cells, can be optimized. Moreover, based on the UCS test results, the UCS values on the centrifugation treatment samples were 
higher than the samples with the filtration treatments.

\section{Acknowledgments}

This research was funded by the Ministry of Research and Technology/National Research and Innovation Agency of The Republic of Indonesia, grant number 1/E1/KP.PTNBH/2021.

\section{REFERENCES}

[1] V. S. Whiffin, L. A. van Paassen, and M. P. Harkes, "Microbial carbonate precipitation as a soil improvement technique,” Geomicrobiol. J., vol. 24, no. 5, pp. 417-423, 2007.

[2] J. T. DeJong, M. B. Fritzges, and K. Nüsslein, "Microbially induced cementation to control sand response to undrained shear,” J. Geotech. Geoenvironmental Eng., vol. 132, no. 11, pp. 1381-1392, 2006.

[3] H. Yasuhara, D. Neupane, K. Hayashi, and M. Okamura, "Experiments and predictions of physical properties of sand cemented by enzymatically-induced carbonate precipitation,” Soils Found., vol. 52, no. 3, pp. 539-549, 2012.

[4] H. Putra, H. Yasuhara, N. Kinoshita, and A. Hirata, "Application of magnesium to improve uniform distribution of precipitated minerals in 1-m column specimens," Geomech. Eng., vol. 12, no. 5, pp. 803-813, 2017.

[5] H. Putra, H. Yasuhara, N. Kinoshita, and A. Hirata, "Optimization of enzyme-mediated calcite precipitation as a soil-improvement technique: The effect of aragonite and gypsum on the mechanical properties of treated sand," Crystals, vol. 7, no. 2, 2017.

[6] H. Putra, H. Yasuhara, and N. Kinoshita, "Optimum condition for the application of enzyme-mediated calcite precipitation technique as soil improvement method," Int. J. Adv. Sci. Eng. Inf. Technol., vol. 7, no. 6, pp. 2145-2151, 2017.

[7] H. Putra, H. Yasuhara, and N. Kinoshita, “Applicability of natural zeolite for $\mathrm{NH}$-forms removal in enzyme-mediated calcite precipitation technique,” Geosci., vol. 7, no. 3, 2017.

[8] A. Cuccurullo, D. Gallipoli, A. W. Bruno, C. Augarde, P. Hughes, and C. La Borderie, "Earth stabilisation via carbonate precipitation by plant-derived urease for building applications,” Geomech. Energy Environ., p. 100230, 2021.

[9] G. B. S. Pratama, H. Yasuhara, N. Kinoshita, and H. Putra, "Application of soybean powder as urease enzyme replacement on EICP method for soil improvement technique,” IOP Conf. Ser. Earth Environ. Sci., vol. 622, no. $1,2021$.

[10] D. Meisnnehr, H. Putra, and H. Yasuhara, "Utilization of soybean powder as the additional material on calcite precipitation method for improving the strength of liquefiable soil," IOP Conf. Ser. Earth Environ. Sci., vol. 622, no. 1, 2021.
[11] H. S. Baiq, H. Yasuhara, N. Kinoshita, H. Putra, and E. Johan, "Examination of calcite precipitation using plant-derived urease enzyme for soil improvement," Int. J. GEOMATE, vol. 19, no. 72, pp. 231-237, 2020.

[12] S. Lee and J. Kim, “An Experimental Study on Enzymatic-Induced Carbonate Precipitation Using Yellow Soybeans for Soil Stabilization,” KSCE J. Civ. Eng., vol. 24, no. 7, pp. 2026-2037, 2020.

[13] H. Fu, W. Mo, X. Shen, and B. Li, "Impact of centrifugation treatment on enzymatic hydrolysis of cellulose and xylan in poplar fibers with high lignin content,” Bioresour. Technol., vol. 316, no. May, 2020.

[14] H. Putra, H. Yasuhara, N. Kinoshita, D. Neupane, and C.-W. $\mathrm{Lu}$, "Effect of magnesium as substitute material in enzyme-mediated calcite,” Front. Bioeng. Biotechnol., vol. 4, no. 37, pp. 1-9, 2016.

[15] S. I. A. Shah, L. W. Kostiuk, and S. M. Kresta, "The effects of mixing, reaction rates, and stoichiometry on yield for mixing sensitive reactions - Part I: Model development," Int. J. Chem. Eng., vol. 2012, 2012.

[16] A. Almajed, A. Ali, and B. Moghal, "State-of-the-art review of the applicability and challenges of microbial- induced calcite precipitation (MICP) and enzyme-induced calcite precipitation (EICP) Techniques for Geotech...," Crystals, vol. 11, no. 370, pp. 1-22, 2021.

[17] N. Abe, C. Y. Wu, Y. K. Kim, T. Fujii, and K. Abe, "Development of an efficient soymilk cream production method by papain digestion, heat treatment, and low-speed centrifugation,” Biosci. Biotechnol. Biochem., vol. 79, no. 11, pp. 1890-1892, 2015.

[18] Y. Peng, N. Kersten, K. Kyriakopoulou, and A. J. van der Goot, "Functional properties of mildly fractionated soy protein as influenced by the processing pH,” J. Food Eng., vol. 275, p. 109875, 2020.

[19] P. K. Robinson, "Enzymes: principles and biotechnological applications,” Essays Biochem., vol. 59, pp. 1-41, 2015.

[20] M. Molenda, M. D. Montross, J. Horabik, and I. J. Ross, "Mechanical Properties of Corn and Soybean Meal,” Trans. Am. Soc. Agric. Eng., vol. 45, no. 6, pp. 1929-1936, 2002.

[21] I. Ahenkorah, M. M. Rahman, M. R. Karim, S. Beecham, and C. Saint, "A Review of Enzyme Induced Carbonate Precipitation (EICP): The Role of Enzyme Kinetics," Sustain. Chem., vol. 2, no. 1, pp. 92-114, 2021.

[22] H. S. Baiq, H. Putra, A. Almajed, N. Kinoshita, and H. Yasuhara, "Efficacy of organic additive in EICP technique for soil improvement," 2020 World Congr. Adv. Civil, Environ. Mater. Res., pp. 25-28, 2020.

[23] H. Rohy, M. Arab, W. Zeiada, M. Omar, A. Almajed, and A. Tahmaz, "One phase soil bio-cementation with eicp-soil mixing," World Congr. Civil, Struct. Environ. Eng., pp. 18, 2019.

[24] X. Sun, L. Miao, and L. Wu, “Applicability and Theoretical Calculation of Enzymatic Calcium Carbonate Precipitation for Sand Improvement," Geomicrobiol. J., vol. 37, no. 4, pp. 389-399, 2020.

[25] Y. Chen, Y. Gao, C. W. W. Ng, and H. Guo, "Bio-improved hydraulic properties of sand treated by soybean urease 
induced carbonate precipitation and its application Part 1: Water retention ability," Transp. Geotech., vol. 27, no. December 2020, p. 100489, 2021.

[26] J. T. DeJong, B. M. Mortensen, B. C. Martinez, and D. C. Nelson, "Bio-mediated soil improvement," Ecol. Eng., vol. 36, no. 2, pp. 197-210, 2010.

[27] D. Neupane, H. Yasuhara, N. Kinoshita, and H. Putra, "Distribution of grout material within 1-m sand column in insitu calcite precipitation technique,” Soils Found., vol. 55, no. 6, pp. 1512-1518, 2015.

[28] M. A. Felicetti, F. Piantino, J. R. Coury, and M. L. Aguiar,
"Influence of removal time and particle size on the particle substrate adhesion force,” Brazilian J. Chem. Eng., vol. 25, no. 1, pp. 71-82, 2008.

[29] G. Khanlari, B. Rafiei, and Y. Abdilor, "Evaluation of strength anisotropy and failure modes of laminated sandstones,” Arab. J. Geosci., vol. 8, no. 5, pp. 3089-3102, 2015.

[30] A. Almajed, H. K. Tirkolaei, E. Kavazanjian, and N. Hamdan, "Enzyme Induced Biocementated Sand with High Strength at Low Carbonate Content,” Sci. Rep., vol. 9, no. 1, pp. 1-7, 2019. 